\title{
POLIGINIA EM SICALIS FLAVEOLA BRASILIENSIS \\ (GMELIN, 1789) (PASSERIFORMES, EMBERIZIDAE)
}

\section{LUIZ OCTAVIO MARCONDES MACHADO}

\section{ABSTRACT}

During observations that took place at the Sitio Monte Mor, Municipality of Limeira, São Paulo, two cases of bigamy among Sicalis flaveola brasiliensis were studied. The females occupied the same territory and built the nests close to one another. No aggression was observed between them, when one would enter each others' nest. The male fed the nestling of both females, even when the brood occurred simultaneously.

\section{INTRODUÇĀO}

Dois tipos de poligamia são comumente aceitos: a poliginia, quando o macho fertiliza os óvulos de duas ou mais fêmeas e a poliandria, quando uma fêmea copula com dois ou mais machos (Van Tyne \& Berger, 1976).

$\mathrm{O}$ relacionamento entre macho e fêmea em passeriformes está provavelmente ligado à disponibilidade de alimento e à estrutura da vegetação, embora, até o momento, não se tenha uma base precisa para afirmar, com certeza, quais os principais fatores envolvidos. Acredita-se que a abundância alimentar constitua um fator seletivo importante para a maioria destas espécies poligínicas que possuem ninhos não coloniais (Wittenberger, 1981). Para Zimmerman (1966), a ocorrência de poliginia em Spiza americana se deve não à extensão dos territórios de machos monógamos e poligínicos, mas sim à disponibilidade diferencial de locais para a construção de ninho.

Segundo Orians (1969, apud Barnett, 1981), parece vantajoso para uma fêmea acasalar-se com um macho, mesmo já acasalado, que habita um território com muito alimento, pela facilidade em alimentar a prole.

$\mathrm{Na}$ América do Norte e África a presença de regiões alagadiças, com variações locais quanto à disponibilidade de alimento favorece a ocorrência de espécies poligínicas. Já com pássaros europeus, dos quais $5 \%$ são poligínicos o habitat alimentar e os nichos destas espécies não confirmam esta hipótese (Barnett, 1981).

De acordo com Carey \& Nolan (1975), muitos casos de poliginia ocasional em aves poderiam ser encontrados, relacionados a riquezas dos diferentes territórios. Estes autores sugerem que a variação de disponibilidade de alimento ocasionou o aparecimento de poliginia em Passerina cyanea em um habitat rico, onde uma pequena proporção de fêmeas unem-se a um macho já acasalado, ao invés de terem um relacionamento monogâmico com machos solteiros, ocorrendo, portanto, uma considerável flexibilidade no sistema de acasalamento de uma espécie. Um caso oposto acontece com Troglodytes troglodytes, espécie tipicamente poligâmica que possui raças monógamas em ilhas da costa britânica, onde a disponibilidade de alimento é escassa (Armstrong 1955, apud Grzimek, 1977).

A ocorrência de poliginia em Sicalis flaveola brasiliensis (Gmelin, 1789) parece ser incomum. O comportamento reprodutivo dessa espécie foi estudado por Buschinelli (1971), em dois casais monogâmicos e por Machado (1980), em 28 casais, onde apenas 2 machos estavam acasalados com duas fêmeas ao mesmo tempo. A observação de poliginia em Sicalis flaveola brasisiliensis, assim como o estudo detalhado desse padrão comportamental são aqui apresentados.

Departamento de Zoologia, Instituto de Biologia, Universidade Estadual de Campinas, - 13.100 Campinas, SP. 
Foram feitas observações durante duas estaçōes reprodutivas: a primeira no período de 11 de fevereiro de 1976 a 12 de maio de 1976 e a outra de 30 de setembro de 1976 a 13 de janeiro de 1977.

O estudo foi realizado no Sítio Monte Mor, situado no Município de Limeira, SP. Os pássaros alimentavam-se principalmente da ração fornecida aos animais domésticos e utilizavam como local para construção do ninho, latas de conserva vazias, semi-abertas em um dos lados, que haviam sido colocadas em diferentes locais pelos moradores do sítio.

As observações foram realizadas com auxílio de binóculo Asahi Pentax ZCF $7 \times 50$.

No primeiro período de estudo foram observados um macho adulto, uma fêmea adulta e uma fêmea jovem (com plumagem característica de pássaros com menos de um ano). No segundo período foram observados um macho jovem (com plumagem característica de pássaros com menos de um ano), uma fêmea adulta e uma fêmea com plumagem de um ano. Provavelmente as fêmeas eram as mesmas nos dois períodos.

\section{Primeiro Caso:}

\section{RESULTADOS}

Os indivíduos envolvidos no primeiro caso de poliginia, observados du. rante $010^{\circ}$ semestre de 1976 , embora não tivessem sido anilhados, eram facilmente identificáveis. O macho e as duas fêmeas pousavam próximos e se alimentavam juntos, no chão.

A fêmea jovem e a adulta tinham ninhos em latas de conserva semi-abertas situadas a aproximadamente $30 \mathrm{~m}$ uma da outra. O ninho da fêmea adulta estava localizado em uma lata presa sob o beiral do telhado de uma casa e o da fêmea jovem em um poste a cerca de $2 \mathrm{~m}$ de altura. A fêmea jovem, durante a fase de construção visita o ninho da fêmea adulta.

A fêmea adulta iniciou a ovipostura antes que a jovem. A ovipostura das duas fêmeas foi constituída de 4 ovos, dos quais todos eclodiram.

Os ninhegos da fêmea adulta foram alimentados por ela e pelo macho; cerca de 6 dias após terem abandonado o ninho, a fêmea adulta visitou o ninho da fêmea jovem que, na ocasião, não estava à vista mas o macho encontrava-se nas proximidades.

Os filhotes da fêmea jovem saíram do ninho 16 dias após os da fêmea adulta e foram alimentados conjuntamente pela fêmea jovem e pelo macho.

No período em que havia filhotes nos dois ninhos o macho alimentou a todos, simultaneamente.

Dos 4 filhotes da fêmea jovem, dois se desenvolveram menos que os demais e um deles morreu.

A fêmea adulta efetuou uma segunda ovipostura de 4 ovos. A fêmea jovem, após 14 dias de os filhotes haverem saído do ninho, iniciou, juntamente com o macho, a construção de um outro ninho no beiral do telhado, entre as telhas e o forro da casa a aproximadamente $0,50 \mathrm{~m}$ do ninho da fêmea adulta. A fêmea jovem pôs 4 ovos.

Os 4 filhotes da segunda ovipostura da fêmea adulta saíram do ninho quando a fêmea jovem já havia posto 3 ovos de sua segunda ovipostura. Todos os 4 ovos da fêmea jovem eclodiram.

\section{Segundo Caso:}

No $2 .^{\circ}$ semestre de 1976 , após a época não reprodutiva, foi observado um relacionamento entre uma fêmea adulta, uma fêmea com plumagem de um ano e um macho com plumagem de menos de um ano. Provavelmente as fêmeas eram as mesmas observadas no $10^{\circ}$ semestre.

A fêmea adulta construiu o ninho no mesmo local utilizado no período anterior, em uma lata sob o telhado e pôs 5 ovos. Aparentemente abandonou 
este ninho e, juntamente com o macho, passou a construir um ninho em uma fenda no alto de um mourão de cerca, situado próximo à casa, onde se encontrava o outro ninho. $\mathrm{Na}$ fase inicial de construção o macho jovem tentou copular com a fêmea adulta.

A fêmea jovem entrava na fenda onde estava sendo construído o ninho como também no ninho abandonado pela fêmea adulta. Nos dois ninhos nunca ocorreu agressão, embora estivessem próximos o macho e a fêmea adulta.

A fêmea jovem foi observada levando crina de cavalo para a forração do ninho da fêmea adulta, no mourão. Uma das vezes em que estava com este material no bico, junto ao ninho, adotou a postura de solicitação, próxima ao macho e a fêmea adulta. A fêmea adulta bicou o material próximo ao bico da fêmea jovem e se afastou.

No ninho do mourão foram postos 5 ovos, incubados pela fêmea jovem. Durante o período de incubação, a fêmea adulta, juntamente com o macho, visitava fendas em mourões nos arredores. O macho era sempre o primeiro a entrar na fenda, saía e em seguida a fêmea adulta também entrava e logo saía. Voavam juntos para outro mourão e repetiam este padrão comportamental. A fêmea adulta chegou mesmo a entrar na fenda onde a fêmea jovem incubava os 5 ovos; a fêmea jovem saiu rapidamente, só retornando após a saída da fêmea adulta. O macho desta vez não entrou.

Dos 5 ovos, dois desapareceram e os 3 restantes foram cobertos com crina.

A fêmea adulta pôs três ovos no ninho do mourão, dos quais todos eclodiram. A fêmea jovem pôs, no ninho da lata sob o beiral do telhado, 5 ovos que também eclodiram.

$\mathrm{O}$ macho foi observado agredindo um macho adulto que invadiu seu território, ocasionando a fuga do invasor.

\section{DISCUSSÃO}

Os casos de poliginia podem trazer algumas desvantagens. Os machos com duas ou mais ninhadas nidícolas simultâneas tendem a diminuir os cuidados dispensados a cada uma ou terão que aumentar o tempo e a energia necessários para alimentá-las. Além disso, pode ocorrer excesso de utilização de recursos disponíveis e atração de predatores para o território, devido a um maior número de indivíduos habitando-o. Entretanto estas desvantagens podem ser compensadas. De acordo com as hipóteses de Verner \& Willson (1966, apud Carey \& Nolan, 1975) e Orians (1969, apud Carey \& Nolan, 1975), e se recursos críticos estão desigualmente distribuídos podem ocorrer territórios mais providos de recursos, e outros menos providos. Uma fêmea, que se une com um macho já acasalado que habita um território rico em recursos críticos pode ter mais sucesso reprodutivo do que se ela se acasalar com um macho solteiro, que habita um território pobre em recursos. Uma vez estabelecida a poliginia sob estas circunstâncias, ocorrerá uma maior competição de machos por fêmeas. Isto acarretará advertência vocal prolongada, dimorfismo sexual marcante, redução drástica ou eliminação de cuidados parentais pelos machos, e, se machos jovens perderem na competição por fêmeas, a maturação de caracteres empregados na atração de fêmeas ou na competição com outros machos será retardada.

Com relação ao caso de poliginia observado em Sicalis flaveola, o território utilizado era de fato rico em recursos, representados pelo alimento fornecido a animais domésticos. Mas o macho dispensava cuidados à prole, alimentando os filhotes, mesmo quando as duas fêmeas possuem filhotes simultaneamente. O segundo macho que apresentou poliginia era macho jovem, 0 que não influiu no acasalamento e na competição com outros machos. Provavelmente a poliginia é ocasional em $S$. flaveola, uma vez que foi observada em apenas um território e possivelmente com o mesmo par de fêmeas. A permanência de uma fêmea jovem em um território é considerada incomum, pois segundo observações de Machado (1980) os filhotes emancipados são mantidos afastados dos territórios.

Em Dolichonyx oryzivorus, espécie reconhecidamente poligínica, o macho acasalado com duas fêmeas só alimenta, na maioria das vezes, a ninhada da 
primeira fêmea com quem se acasalou, aparentemente porque os filhotes mais velhos têm valor reprodutivo mais alto. Em alguns casos pode alimentar a ninhada da segunda fêmea quando as condições nutricionais são favoráveis (Wittenberger, 1980). No caso estudado, o macho de Sicalis flaveola alimentava as ninhadas das duas fêmeas simultaneamente, cu porque não existia uma especialização como no caso de $D$. oryzivorus, ou devido à abundância de alimento. Em Geothlypis trichas onde a poliginia também é ocasional, foi observado o macho alimentando a ninhada das duas fêmeas (Powell \& Jones, 1978).

Além do caso observado, a poliginia pode também ocorrer em outras espécies monogâmicas. Segundo Logan \& Rulli (1981), ocorreu poliginia em Mimus polyglottos, espécie altamente monogâmica, quando $\circ$ macho proprietário de um território desapareceu, e o macho do território vizinho se acasalou com a viúva. Entretanto, neste caso, as fêmeas permanecem em seus respectivos territórios iniciais, enquanto que o macho ampliou 0 seu anexando o do vizinho, que havia ficado sem macho. Willson (1966) em Melospiza georgiana encontrou 2 machos bígamos em 12 observados em regiões alagadiças. As fêmeas desta espécie possuíam também subterritórios independentes no território de cada macho. As fêmeas de S. flaveola, por outro lado, habitavam o mesmo território, com ninhos próximos.

Iarus argentatus pode apresentar poliginia ocasional, provavelmente quan. do o número de fêmeas é maior que o de machos (Shugart, 1980). Powell \& Jones (1978) sugerem que a reduzida competição intra-específica seja a responsável pelo aparecimento de um caso de bigamia em Geothlypis trichas. Para S. flaveola tal hipótese não é válida, pois um macho solteiro foi expulso do território pelo macho proprietário, levando a crer que a razão entre machos e fêmeas na área estudada não devia favorecer as fêmeas. No caso de poliginia em Aphelocoma c. coerulescens, Woolfenden (1976) observou agressões entre as duas fêmeas, podendo mesmo uma delas ter quebrado os ovos da outra. Pelo contrário, as duas fêmeas de $S$. flaveola, não se agrediam, auxiliando-se mutuamente quanto a cuidados à prole e construção no ninho. Em Zonotrichia leucophrys as fêmeas foram observadas juntas se alimentando, acompanhadas ou não pelo macho, sem que ocorresse hostilidade entre ambas (Petrinovich \& Patterson, 1978). Assim como em S. flaveola, uma das fêmeas era adulta e a outra jovem.

\section{AGRADECIMENTOS}

A Eloisa Helena Morgado e Antonia Cecília Zacagnini Amaral pela dis. cussão e leitura do texto; a Suzanne M. Bennett pela revisão do "Abstract"; ao Sr. Dante Carrari, proprietário do Sítio Monte Mor, pelas facilidades concedidas na pesquisa de campo.

\section{REFERENCIAS}

Barnett, S. A., 1981. Modern Ethology. The science of animal behavior, xi +705 pp., il. Oxford University Press, N. York.

Buschinelli, A., 1971. Contribuição ao estudo da biologia do canário da terra. Ciênc. Cult., S Paulo 23(2): 163-166.

Carey, M. \& V. Nolan, Jr., 1975. Polygamy in indigo buntings: A hypothesis tested. Science, N. York 190: 1296-1297.

Grzimek, B., 1977. Grzimek's encyclopaedia of ethology, xx +705 pp., il. Van Nostrand Reinhold, N. York.

Logan, C. A. \& M. Rulli, 1981. Bigamy in a male mockingbird. Auk 98: 385-386.

Machado, L. O. M., 1980. Alguns aspectos do comportamento e da biologia de Sicalis flaveola (Linnaeus, 1766) (Passeriformes, Emberizidae). Tese de Doutoramento (Zoologia), Instituto de Biociências, Universidade de São Paulo.

Petrinovich, L. \& T. L. Patterson, 1978. Polygyny in the white-crowned sparrow (Zonotrichia leucophrys). Condor 80: 99-100. 
Powell, G. V. N. \& H. L. Jones, 1978. An observation of polygyny in the common yellowthroat. Wilson Bull. 90(4): 656-657.

Shugart, G. W., 1980. Frequency and distribution of polygyny in Great Lakes herring hulls in 1978. Condor 82: 426-429.

Van Tyne, J. \& A. J. Berger, 1976. Fundamentals of ornithology, xviii +808 pp., il. Wiley and Sons, N. York.

Zimmerman, J. L., 1966. Polygyny in the dickcissel. Auk 83: 534-546.

Willson, M. F., 1966. Polygamy among swamp sparrows. Ibid. 83: 666.

Wittenberger, J. F., 1980. Feeding on secondary nestlings by polygynous male bobolinks in Oregon. Wilson Bull. 92(3): 330-340.

Wittenberger, J. F., 1981. Animal social behavior, xi + 722 pp., il. Duxbury, Boston.

Woolfenden, G. E., 1976. A case of bigamy in the Florida scrub jay. Auk 93: $443-450$. 